\title{
UTILIZAÇÃO DE ÓXIDO DE BORO COMO FLUXANTE DE ESCÓRIAS SINTÉTICAS DESSULFURANTES*
}

\author{
Jorge Luís Coleti ${ }^{1}$ \\ Felipe Fardin Grillo² \\ José Roberto de Oliveira ${ }^{3}$ \\ Jorge Alberto Soares Tenório ${ }^{4}$
}

\section{Resumo}

A siderurgia mundial vive um momento de excesso de oferta, com isso as empresas necessitam reduzir custos por meio da melhora de processos e/ou através da substituição por matérias primas alternativas às convencionalmente utilizadas. Este trabalho trata justamente deste tópico e busca substituir a fluorita por outra fonte de fluxante, neste caso, o óxido de boro. Neste trabalho o óxido de boro foi adicionado a escórias sintéticas num banho de aço à $1600^{\circ} \mathrm{C}$. Foram realizados testes com proporções de 3\%, 5\% e 7\% de óxido de boro na composição das escórias. A fusão foi realizada em atmosfera inerte de argônio em um forno de resistência de dissiliceto de molibdênio. Amostras de aço foram removidas periodicamente a cada 5 minutos até os 25 minutos de experimento. Estas amostras foram analisadas em um espectrômetro de infravermelho. Os resultados indicam a viabilidade técnica para a aplicação do óxido de boro como substituinte da fluorita.

Palavras-chave: Dessulfuração; Óxido de boro; Fluorita.

\section{USE OF BORON OXIDE AS FLUX IN DESULFURIZING SYNTHETICS SLAGS}

\begin{abstract}
The global steel industry is facing a period of oversupply, thus companies need to reduce costs by improving processes and/or by using alternative raw materials. This work focuses precisely about this topic and seeks to replace the fluorite by another source of slag flux. In this paper, boron oxide was added to synthetic slags at $1600^{\circ} \mathrm{C}$ in a steel bath. Tests were carried out using 3\%, 5\% and $7 \%$ of boron oxide in the composition of the slag. The fusion was performed under an argon inert atmosphere in an electrical furnace with molybdenum disilicide resistance. Steel samples were removed periodically each 5 minutes until 25 minutes of the experiment. These samples were analyzed by an infrared spectrometer. The results showed the technical feasibility of boron oxide application as a substituent of fluorite.
\end{abstract}

Keywords: Desulfurization; Boron oxide; Fluorite.

1 Engenheiro Metalurgista, Mestre em Ciências, Doutorando na Escola Politécnica da Universidade de São Paulo (USP), São Paulo, Brasil.

2 Doutor em Engenharia Metalúrgica e de Materiais, Escola Politécnica, Universidade de São Paulo (USP), São Paulo, Brasil.

3 Professor Doutor do programa de pós-graduação em Engenharia Metalúrgica e de Materiais, Instituto Federal de Educação do Espírito Santo (IFES), Vitória, Brasil.

4 Professor Titular, Programa de Pós-graduação em Engenharia Química, Escola Politécnica, Universidade de São Paulo (USP), São Paulo, Brasil. 


\section{INTRODUÇÃO}

O refino de aço é um dos setores da siderurgia que necessita de constante investimento em pesquisa, devido a sua importância no processo siderúrgico. A etapa de dessulfuração nos aços, cuja reação global é representada pela Equação (1) [1], é realizada em reatores de refino secundário, ou ainda, em alguns casos específicos, durante o vazamento do reator de refino primário para a panela de transferência[2].

$$
\underline{S}+O^{2-} \leftrightarrow S^{2-}+\frac{1}{2} O_{2}
$$

O mercado mundial de aço bruto produziu em 2014 cerca de 1,6 bilhões de toneladas[3]. Destes, o Brasil contribuiu com 2,1\% da produção mundial e com $75 \%$ da produção da América do Sul. Enquanto isso, a demanda estimada de aço no mundo em 2014 foi de 1,5 bilhões de toneladas[4], gerando um excedente de pelo menos 100 milhões de toneladas no mundo.

Outra necessidade da indústria siderúrgica é a substituição da fluorita $\left(\mathrm{CaF}_{2}\right)$, que é o principal fluidificante de escórias, mas um potencial gerador de gases fluoretados. Estes gases são agressivos ao meio ambiente, e até o momento não existe um substituto a nível industrial para ser aplicado. Diversos componentes foram testados em pesquisas[5-9], alguns deles são aplicados na composição das escórias (barrilha, sodalita, carbureto de cálcio, óxido de titânio). Um composto que vem sendo estudado é óxido de boro. Diversas pesquisas[10-14], indicam o seu potencial como substituinte da fluorita no que diz respeito a viscosidade e ao abaixamento da temperatura de fusão da escória, contudo há pouca referência a respeito da influência do mesmo na dessulfuração do aço.

O óxido de boro funde-se a $445^{\circ} \mathrm{C}$ [10] e a diminuição na temperatura de fusão da escória faz com que seja praticamente toda líquida segundo o programa FactSage na temperatura de execução do experimento. A escória totalmente líquida promove um aumento na cinética de dessulfuração do aço, com isso, espera-se que seja mais facilmente removido o enxofre da composição do banho, todavia, é necessário garantir a atividade da cal igual a unidade para que se tenha certeza de que durante a dessulfuração não faltará cal para a reação [15].

Desta forma, este artigo utiliza o óxido de boro em escórias dessulfurantes para aço na temperatura de $1600^{\circ} \mathrm{C}$, com o objetivo de avaliar a dessulfuração do aço utilizando-se deste óxido no lugar da fluorita.

\section{MATERIAIS E MÉTODOS}

O trabalho foi realizado segundo as etapas a seguir:

- Caracterização das matérias primas.

- Determinação das misturas dessulfurantes

- Realização dos experimentos de dessulfuração

- Análise das amostras de aço via espectroscopia de infravermelho

- Análise dos resultados

\subsection{Caracterização da matéria prima}

A alumina, sílica, óxido de magnésio e fluorita foram doadas por empresas metalúrgicas e foram recebidas já com a composição química informada.

O $\mathrm{CaO}$ utilizado era de padrão analítico, com no mínimo $92 \%$ de $\mathrm{CaO}$. No caso do óxido de boro, ele foi obtido a partir da decomposição térmica do ácido bórico, com comprovação de fase realizada por meio de difração de raios-x. 
$\mathrm{Na}$ sequência, com as matérias primas devidamente secas em estufa. Estas foram pesadas e misturadas nas proporções determinadas para cada mistura. A composição química das matérias primas é mostrada na Tabela 1.

Tabela 1. Composição química das matérias primas utilizada nas misturas dessulfurantes.

\begin{tabular}{ccccccc}
\hline Elementos & Cal & Alumina & Sílica & $\begin{array}{c}\text { Oxido de } \\
\text { Magnésio }\end{array}$ & $\begin{array}{c}\text { Oxido } \\
\text { de boro }\end{array}$ & Fluorita \\
\hline $\mathrm{SiO}_{2}$ & 1,6 & - & 99,0 & 1,0 & & - \\
\hline $\mathrm{Fe}_{2} \mathrm{O}_{3}$ & 0,4 & - & - & 2,0 & & - \\
\hline $\mathrm{Al}_{2} \mathrm{O}_{3}$ & 0,4 & 99,0 & - & 1,0 & & - \\
\hline $\mathrm{MnO}$ & - & - & - & 1,2 & & - \\
\hline $\mathrm{CaF}_{2}$ & - & - & - & - & & 99,0 \\
\hline $\mathrm{B}_{2} \mathrm{O}_{3}$ & & & & & 99,0 & \\
\hline $\mathrm{CaO}$ & 92,9 & - & - & 0,8 & & - \\
\hline $\mathrm{MgO}$ & 0,5 & - & - & 94 & & - \\
\hline $\mathrm{PF}$ & 2,9 & - & - & - & & - \\
\hline
\end{tabular}

\subsection{Determinação das misturas dessulfurantes}

Foram testadas três misturas dessulfurantes para a fluorita e outros três misturas para o óxido de boro, com 3\%, 5\% e 7\% destes componente em cada experimento. Estas misturas foram analisadas no programa FactSage afim de se predizer o enxofre de equilíbrio no aço. A Tabela 2 ilustra a composição química das misturas dessulfurantes testadas nos experimentos.

Tabela 2. Composição química das misturas dessulfurantes adicionadas.

\begin{tabular}{ccccccc}
\hline Mistura & $\mathrm{Al}_{2} \mathrm{O}_{3}(\%)$ & $\mathbf{C a O}(\%)$ & $\mathbf{M g O}(\%)$ & $\mathrm{SiO}_{2}(\%)$ & $\mathrm{B}_{2} \mathrm{O}_{3}(\%)$ & $\mathrm{CaF}_{2}(\%)$ \\
\hline CF7 & 30,0 & 56,0 & 6,0 & 1,0 & 0,0 & 7,0 \\
\hline CF5 & 28,0 & 60,0 & 6,0 & 1,0 & 0,0 & 5,0 \\
\hline CF3 & 27,0 & 63,0 & 6,0 & 1,0 & 0,0 & 3,0 \\
\hline CB7 & 20,0 & 66,0 & 6,0 & 1,0 & 7,0 & 0,0 \\
\hline CB5 & 25,0 & 63,0 & 6,0 & 1,0 & 5,0 & 0,0 \\
\hline CB3 & 30,0 & 60,0 & 6,0 & 1,0 & 3,0 & 0,0
\end{tabular}

As siglas CF indicam que a escória possui fluorita, as CB que a escória possui óxido de boro e a numeração indica a porcentagem destes componentes presente, no caso $3,5,7 \%$.

\subsection{Experimento de dessulfuração}

Para a fusão do metal a $1600^{\circ} \mathrm{C}$ foi utilizado um forno de resistência de dissiliceto de molibdênio em atmosfera inerte de argônio. Em cada experimento foram fundidos aproximadamente $1 \mathrm{~kg}$ de aço e utilizou-se uma proporção de 10kg/ton de aço para adição da escória. Após a completa fusão do metal, uma amostra inicial de aço era retirada, com o auxílio de um amostrador de quartzo à vácuo. Na sequência o agitador era posicionado, de acordo com a Figura 1, e após isto, adicionava-se a mistura 
dessulfurante e alumínio para garantir que o metal estivesse desoxidado, com o auxílio de um tubo de aço inoxidável.

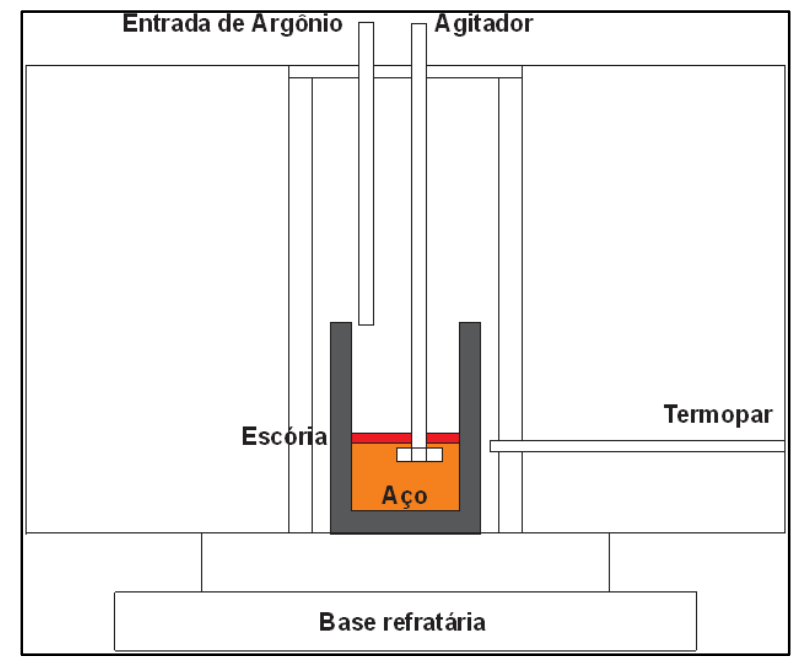

Figura 1. Câmara de reação do forno utilizado nos experimentos mostrando o posicionamento do agitador, da lança de argônio e do termopar.

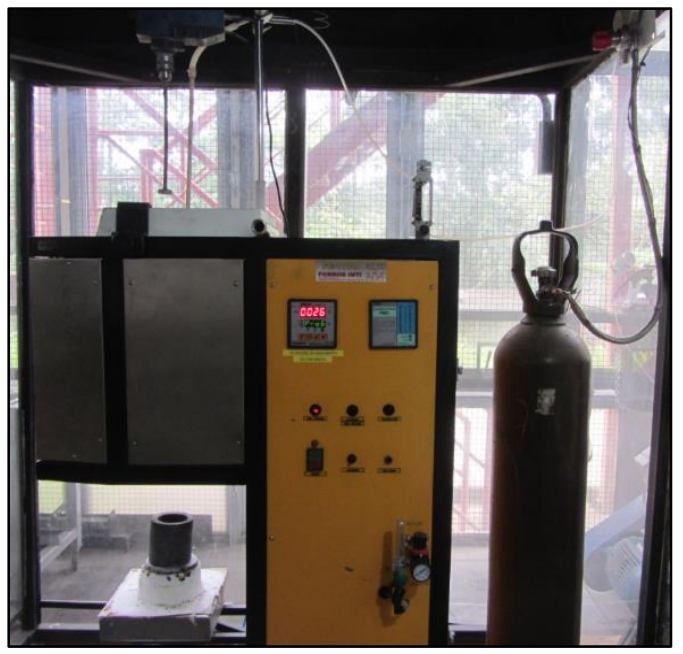

Figura 2. Aparato experimental utilizado nos ensaios de dessulfuração do aço

A adição da mistura dessulfurante e o início da agitação indicavam o início do tempo de dessulfuração, que foi até os 25 minutos e com retirada de amostras a cada 5 minutos. Com isso cada um dos seis experimentos teve 6 amostras a serem analisadas. O aparato experimental utilizado para os experimentos pode ser visualizado na Figura 2.

\subsection{Análise das amostras de aço via espectroscopia de infravermelho}

As amostras iniciais de aço foram analisadas em um espectrômetro de emissão ótica Oxford, modelo Foundry Master Pró, na sequência uma média foi feita para se obter um valor padronizado de composição inicial. Já as amostras de aço colhidas durante cada experimento foram analisadas em um espetrômetro de infravermelho, LECO CS 230.

\subsection{Análise dos resultados}

Os resultados foram estudados de acordo com a eficiência de dessulfuração em diagramas de eficiência versus tempo.

A eficiência pode ser calculada segundo a Equação (2):

$$
\% D e S=\left(\frac{S_{i}-S_{f}}{S_{i}}\right) * 100
$$

Além disso, também utilizou-se dos resultados do FactSage para se obter uma relação entre a quantidade de fase líquida e fase sólida presentes em cada escória 


\section{RESULTADOS E DISCUSSÃO}

A composição química inicial do aço SAE 1020 determinada por espectrometria de emissão ótica é ilustrada na Tabela 3.

Tabela 3. Composição química inicial do aço utilizado nos experimentos.

\begin{tabular}{ccccccc}
\hline $\mathbf{C}$ & $\mathbf{M n}$ & $\mathbf{S i}$ & $\mathbf{P}$ & $\mathbf{S}$ & $\mathbf{A l}$ & $\mathbf{F e}$ \\
\hline 0,2 & 0,7 & 0,25 & 0,02 & 0,0080 & 0,15 & 98,7 \\
\hline
\end{tabular}

Observa-se que o aço possui inicialmente cerca de $80 \mathrm{ppm}$ de enxofre em sua composição, dentro das faixas limites para um aço SAE 1020.

Os resultados da análise química das amostras de aço colhidas durante o experimento são apresentados na Tabela 4.

Tabela 4. Variação do teor de enxofre no aço nos experimentos de dessulfuração.

\begin{tabular}{cccccccc}
\hline Misturas & \multicolumn{7}{c}{ Tempo $(\mathbf{m i n})$} \\
\cline { 2 - 8 } & $\mathbf{0}$ & $\mathbf{5}$ & $\mathbf{1 0}$ & $\mathbf{1 5}$ & $\mathbf{2 0}$ & $\mathbf{2 5}$ & Eficiência \\
\hline CF7 & 80,0 & 29,0 & 26,0 & 28,0 & 29,0 & 28,0 & $65,0 \%$ \\
\hline CF5 & 80,0 & 41,0 & 36,0 & 35,0 & 33,0 & 33,0 & $58,8 \%$ \\
\hline CF3 & 80,0 & 35,0 & 37,0 & 33,0 & 32,0 & 34,0 & $57,5 \%$ \\
\hline CB7 & 80,0 & 71,0 & 41,0 & 27,0 & 26,0 & 27,0 & $66,3 \%$ \\
\hline CB5 & 80,0 & 32,0 & 24,0 & 23,0 & 24,0 & 25,0 & $68,8 \%$ \\
\hline CB3 & 80,0 & 73,0 & 63,0 & 44,0 & 38,0 & 33,0 & $58,8 \%$ \\
\hline
\end{tabular}

Com os dados da Tabela 4 foram construídas as curvas de variação do enxofre em função do tempo, que são apresentados na Figura 3 e na Figura 4.

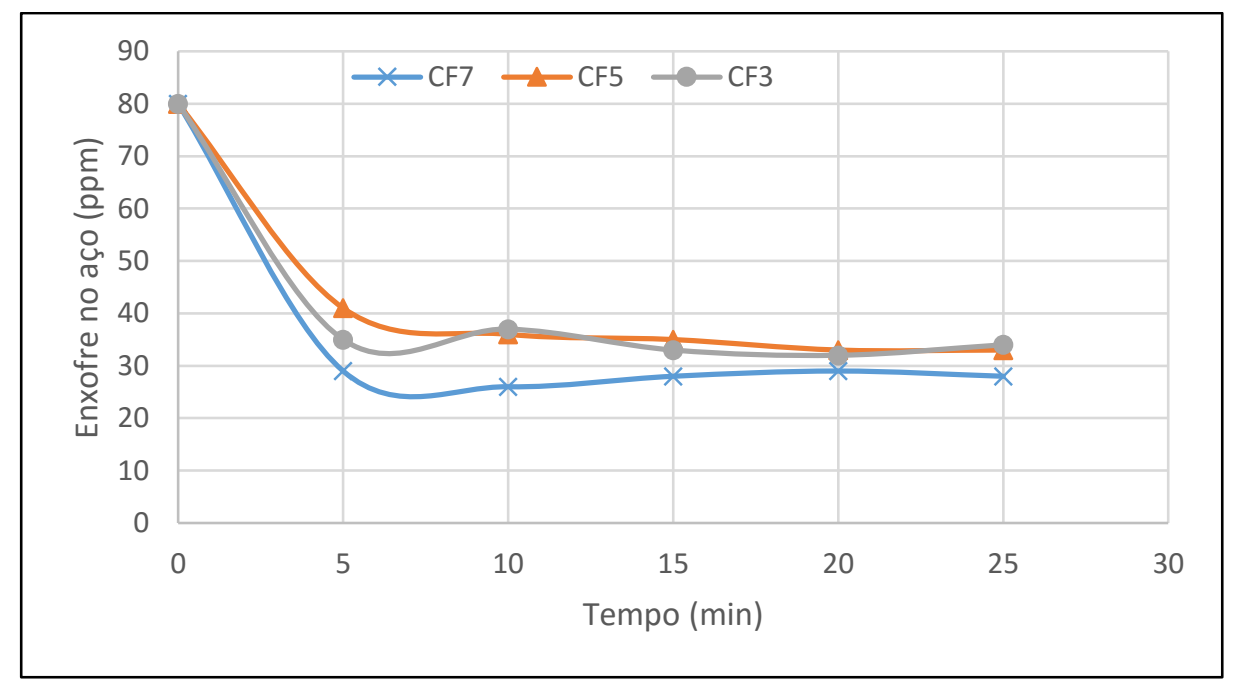

Figura 3. Variação do enxofre em função do tempo de experimentos nas escórias industriais a base de $\mathrm{CaO} / \mathrm{CaF}_{2}$. 


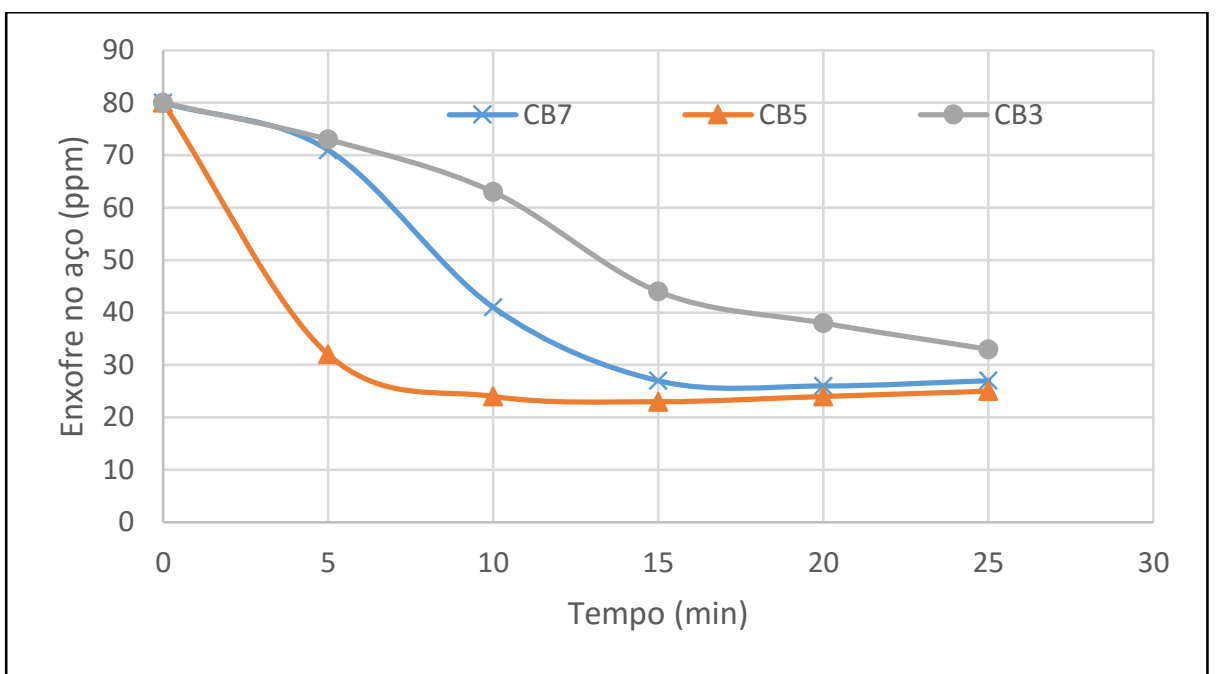

Figura 4. Variação do enxofre em função do tempo de experimentos nas escórias a base de e $\mathrm{CaO} / \mathrm{B}_{2} \mathrm{O}_{3}$.

Nota-se que as escórias com fluorita apresentaram uma acentuada dessulfuração nos primeiros 10 minutos enquanto que os experimentos com óxido de boro esta dessulfuração se estendeu até aproximadamente até os 15 minutos. A escória CB5 apresentou a melhor eficiência de dessulfuração com $68,8 \%$ de remoção de enxofre, com enxofre final de 25ppm.

A Figura 5 apresenta uma análise comparativa da substituição da fluorita por óxido de boro.

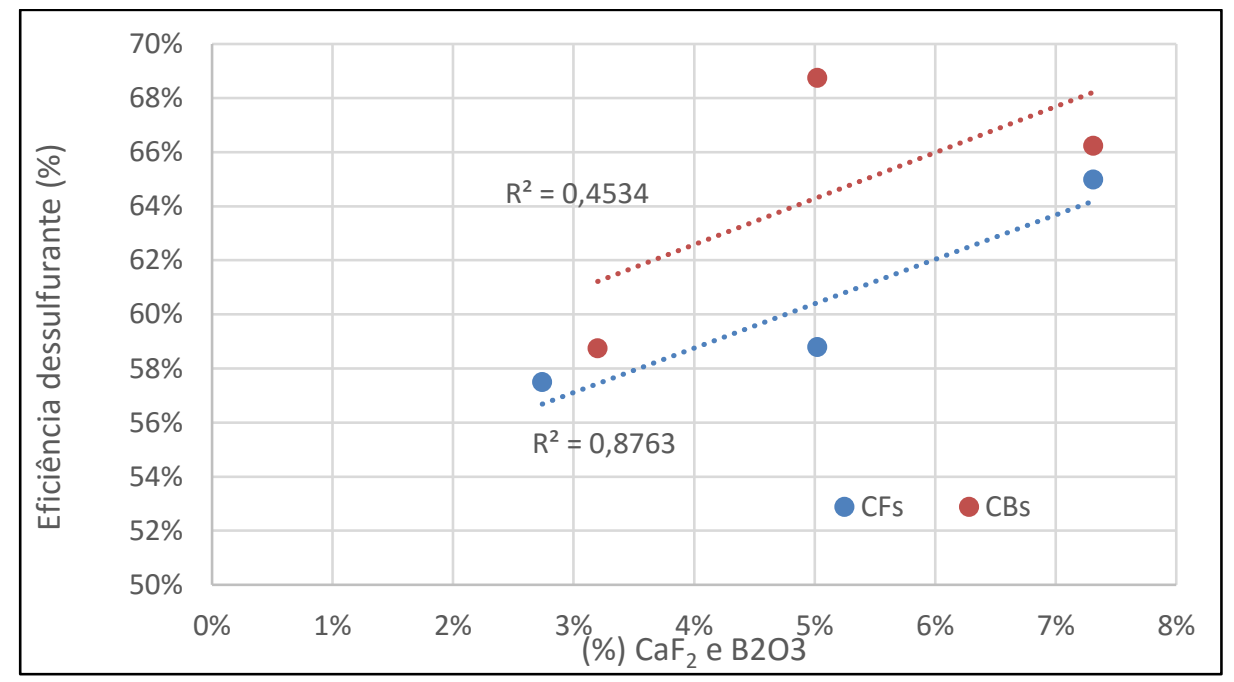

Figura 5. Comparação das eficiências de dessulfuração das escórias com fluorita e com óxido de boro (CFs e CBs).

Observa-se que o óxido de boro apresentou eficiência de dessulfuração superior ao da fluorita, mostrando que pode ser aplicado como substituinte da fluorita. Constatase também que o aumento dos dois fluxantes implica em um aumento da eficiência de dessulfuração. No caso da fluorita a literatura[16] diz que este aumento possui esta tendência até cerca de $12 \%$ de $\mathrm{CaF}_{2}$. Para o óxido de boro todavia não existe uma literatura específica para este componente. Nestes experimentos, a melhor eficiência foi com $5 \%$ de $\mathrm{B}_{2} \mathrm{O}_{3}$. 
Comparando o resultado experimental com o resultado da análise do enxofre de equilíbrio do FactSage, apresentado na Tabela 5, verifica-se que os valores de equilíbrio de enxofre obtidas nos experimentos foram numericamente sempre superiores aos encontrados pelo software. Isto provavelmente deve-se a fatores cinéticos que impedem o alcance do equilíbrio termodinâmico, que é justamente 0 valor fornecido pelo software.

Tabela 5. Teores de equilíbrio em porcentagem (\%) dos elementos presentes no aço calculados pelo programa FactSage.

\begin{tabular}{cccccccc} 
Misturas & Al & Mn & B & Si & C & O & S eq \\
\hline CF7 & 0,15 & 0,76 & 0,00 & 0,24 & 0,21 & $1,39 \mathrm{e}-5$ & $6,05 \mathrm{e}-5$ \\
\hline CF5 & 0,15 & 0,76 & 0,00 & 0,25 & 0,21 & $1,44 \mathrm{e}-5$ & $7,05 \mathrm{e}-5$ \\
\hline CF3 & 0,15 & 0,76 & 0,00 & 0,25 & 0,21 & $1,51 \mathrm{e}-5$ & $9,83 \mathrm{e}-5$ \\
\hline CB7 & 0,09 & 0,76 & 0,0076 & 0,27 & 0,21 & $2,02 \mathrm{e}-5$ & $9,40 \mathrm{e}-5$ \\
CB5 & 0,10 & 0,76 & 0,0045 & 0,27 & 0,21 & $2,09 \mathrm{e}-5$ & $1,16 \mathrm{e}-4$ \\
\hline CB3 & 0,11 & 0,76 & 0,0022 & 0,27 & 0,21 & $2,24 \mathrm{e}-5$ & $1,64 \mathrm{e}-4$ \\
\hline
\end{tabular}

Um outro ponto importante, é que as misturas com fluorita (CF7, CF5, CF3) obtiveram menores concentrações de enxofre final se comparadas as misturas com óxido de boro (CB7, CB5, CB3) como mostra a Figura 6. Fato este que não ocorreu com todos os experimentos práticos.

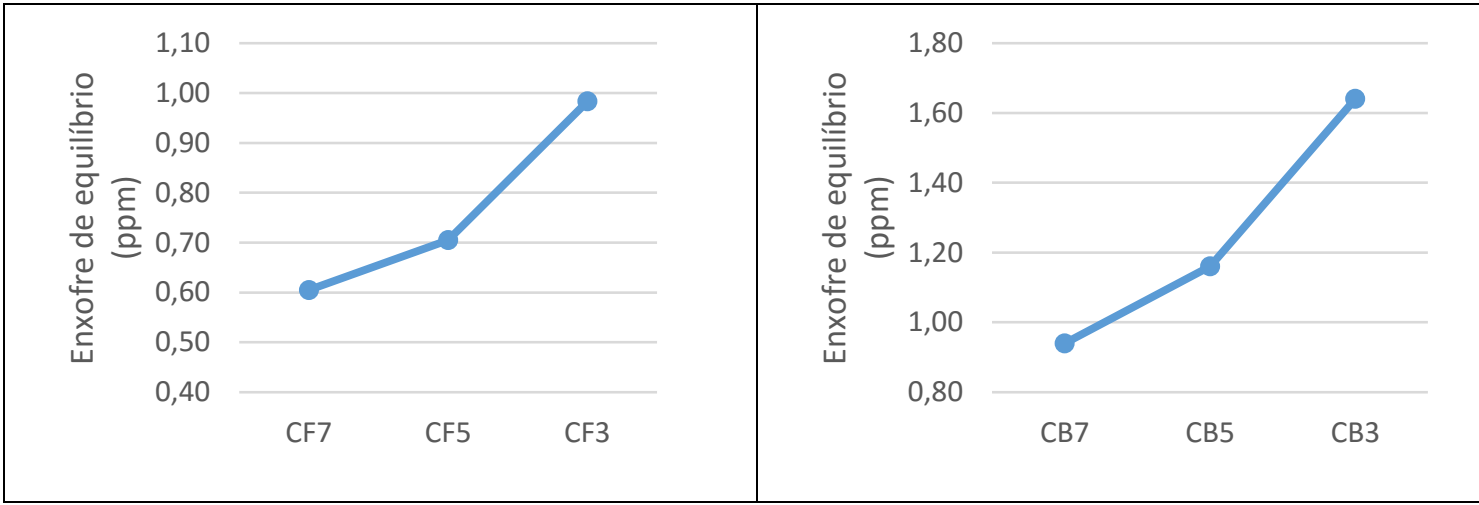

Figura 6. Composição de enxofre de equilíbrio calculados no programa FactSage.

Este resultado sugere que as misturas com fluorita apresentaram maior potencial termodinâmico para remover o enxofre do metal. Além disso, o parâmetro (Seq), calculado (

Tabela 5), apresenta relação direta com o rendimento dessulfurante, uma vez que o rendimento é calculado com base no enxofre final obtido.

As quantidades de fase líquida e sólida presentes na composição das escórias metalúrgicas são de suma importância, pois são elas que definem toda a cinética de dessulfuração do aço. Logo, o FactSage foi fundamental nesta análise. Na Tabela 6 é possível observar estes valores obtidos no FactSage. 
Tabela 6. Dados de equilíbrio entre metal e escória fornecidos pelo FactSage na temperatura de $1600^{\circ} \mathrm{C}$

\begin{tabular}{|c|c|c|c|c|c|}
\hline \multirow[t]{2}{*}{ Misturas } & \multirow{2}{*}{$\begin{array}{l}\text { Total Líquido } \\
\text { (\%) }\end{array}$} & \multicolumn{3}{|c|}{ Fases sólidas (\%) } & \multirow{2}{*}{$\begin{array}{l}\text { Eficiência } \\
\text { \%Des }\end{array}$} \\
\hline & & $\begin{array}{c}\mathrm{CaO} \\
(\%)\end{array}$ & $\mathrm{MgO}(\%)$ & $\begin{array}{c}\text { Total Sólido } \\
(\%)\end{array}$ & \\
\hline CF7 & 90,60 & 6,82 & 2,58 & 9,40 & $65,0 \%$ \\
\hline CF5 & 83,90 & 13,71 & 2,39 & 16,10 & $58,8 \%$ \\
\hline CF3 & 77,19 & 20,69 & 2,12 & 22,81 & $57,5 \%$ \\
\hline CB7 & 79,59 & 19,12 & 1,30 & 20,41 & $66,3 \%$ \\
\hline CB5 & 83,80 & 15,30 & 0,90 & 16,20 & $68,8 \%$ \\
\hline CB3 & 90,66 & 9,01 & 0,34 & 9,34 & $58,8 \%$ \\
\hline
\end{tabular}

Observa-se na Tabela 6 que o aumento das fases sólidas das misturas CFs implica em uma diminuição da eficiência de dessulfuração da escória. Este mesmo fato não ocorre com as misturas CBs, provavelmente devido as composições iniciais destas outras misturas conterem mais $\mathrm{CaO}$ do que as $\mathrm{CFs}$, logo, possivelmente algum fator cinético alterou o processo de dessulfuração.

\section{CONCLUSÃO}

A partir dos resultados obtidos neste trabalho pode-se concluir que, o Óxido de Boro apresentou comportamento muito semelhante ao da fluorita nos experimentos de dessulfuração, obtendo o melhor rendimento com $65 \%$ de eficiência. E também que o auxílio do FactSage foi fundamental para a previsão do comportamento das escórias, no que diz respeito a quantidade de fase sólida e líquida.

\section{Agradecimentos}

À FAPESP pela bolsa 2104/06916-0 concedida.

\section{REFERÊNCIAS}

1 ROSENQVIST, T. Principles of extractive metallurgy. Singapura: McGraw-Hill, 1988. Cap 7. p. 295-323.

2 RIZZO, E.M.D.S. Introduçao aos processos de refino secundário dos aços. São Paulo: Associação brasileira de Metalurgia e Materiais, 2008.

Cap. 6. p. 49-84.

3 Monthly Steel production 2014.<https://www.worldsteel.org> Acesso em: 10 mai. 2015.

4 Short Range Outlook for Apparent Steel Use. <https://www.worldsteel.org> Acesso em: 10 mai. 2015 .

5 TRIBE, T. S.; KINGSTON, P. W.; MACDONALD, J. B.; CALEY, W. F. Reduction of fluorspar consumption in secondary steelmaking. Ironmaking and Steelmaking, n. 2, v. 21, p. 145-149, 1994.

6 VOLKMANN, A. Utilização da sodalita-nefelínica em substituição a fluorita na aciaria da Usiminas. IN: $33^{\circ}$ Seminário de fusão, refino e solidificação dos metais, 2002, Santos. São Paulo, ABM, p. 187-195.

7 SINGH, B. N.; RAVAT, Y. F.; CHATTERJEE, A.; CHAKRAVARTY, P. K. Use of Ilmenite sand as a substitute for fluorspar in Open-Hearth steelmaking. Ironmaking Steelmaking, n. 3, v. 4, p. 170-175, 1977. 
8 DONG, K.; WU, L.; LIU, W.; ZHU, R. Desulfurization of $\mathrm{CaO}-\mathrm{Al}_{2} \mathrm{O}_{3}-\mathrm{SiO}_{2}-\mathrm{TiO} 2$ slag system. ISIJ International, n. 10, v. 54, p. 2248-2254, 2014.

9 SHEVCHENKO, A. F.; VERGUN, A. S.; BULAKHTIN, A. S.; SHEVCHENKO, S. A.; KISLYAKOV, V. G. Improving the ladle desulfurization of hot metal in low sulfur steel production. Journal: Steel in Translation, n. 12, v. 41, 2011.

10 WANG, $\mathrm{H}$.; YANG, L.; et al. Effects of $\mathrm{B}_{2} \mathrm{O}_{3}$ and $\mathrm{CaF}_{2}$ on Melting Temperatures of CaO$\mathrm{SiO}_{2}-\mathrm{Fe}_{2} \mathrm{O}_{3}$ System Fluxes. Journal of Iron and Steel Research, International, v. 20, n. 6 , p. 21-24, 2013.

11 WANG, H.; ZHANG, T.; et al. Effect of $\mathrm{B}_{2} \mathrm{O}_{3}$ on Melting Temperature, Viscosity and Desulfurization Capacity of $\mathrm{CaO}-$ based Refining Flux. ISIJ International, v. 51, n. 5, p. 702-706, 2011.

12 REN, S.; ZHANG, J.; et al. Influence of $\mathrm{B}_{2} \mathrm{O}_{3}$ on Viscosity of High Ti-bearing Blast Furnace Slag. ISIJ International, v. 52, n. 6, p. 984-991, 2012.

13 WANG, H.; ZHU, X.; et al. Compare the Fluxing Effect of Boron Sludge and $\mathrm{CaF}_{2}$ on $\mathrm{CaO}-B a s e d$ Steelmaking Slag. Key Engineering Materials, v. 575-576, p. 382-385, 2013.

14 WANG, H.-M.; LI, G.-R.; et al. CAS-OB refining: slag modification with $\mathrm{B}_{2} \mathrm{O}_{3}-\mathrm{CaO}$ and $\mathrm{CaF}_{2}-\mathrm{CaO}$. Ironmaking \& Steelmaking, v. 34, n. 4, p. 350-353, 2007.

15 GRILLO, F. F. Tese (Doutorado) - Escola Politécnica da Universidade de São Paulo. Departamento de Engenharia Metalúrgica e de Materiais. Estudo da substituição da fluorita por alumina ou sodalita e de cal por resíduo de mármore em escórias sintéticas dessulfurantes,156p. São Paulo, 2015.

16 PRETORIUS, E. The Effect of Fluorspar in Steelmaking Slags. Baker Refractories. [http://etech.Iwbref.com/Downloads/Theory/The\%20Effect\%20of\%20Fluorspar\%20in\%2 0Steelmaking\%20Slags.pdf]. Acesso em: 21/07/2015. 